\title{
Comparative descriptions of eggs from three species of Rhodnius (Hemiptera: Reduviidae: Triatominae)
}

\author{
Carolina M dos Santos ${ }^{1 /+}$, José Jurberg¹, Cleber Galvão', João A da Rosa², Walter C Júnior ${ }^{3}$, \\ José MS Barata ${ }^{3}$, Marcos T Obara ${ }^{3}$
}

1'Laboratório Nacional e Internacional de Referência em Taxonomia de Triatomíneos, Instituto Oswaldo Cruz-Fiocruz, Av. Brasil 4365, 21045900 Rio de Janeiro, RJ, Brasil ²Departamento de Ciências Biológicas, Faculdade de Ciências Farmacêuticas, Universidade Estadual Paulista,

Araraquara, SP, Brasil ${ }^{3}$ Departamento de Epidemiologia, Faculdade de Saúde Pública, Universidade de São Paulo, São Paulo, SP, Brasil

The authors describe and compare the morphological and ultrastructural characteristics of eggs from the three most recent described species of the genus Rhodnius Stål, 1859, which have not previously been studied. These species are Rhodnius colombiensis (Mejia, Galvão \& Jurberg 1999), Rhodnius milesi (Carcavallo, Rocha, Galvão \& Jurberg 2001) and Rhodnius stali (Lent, Jurberg \& Galvão 1993). The results revealed that there are similarities in the exochorial architecture of optical microscopy and scanning electron microscopy; these include the predominance of hexagonal cells that are common to all Rhodnius species and variable degrees of lateral flattening, which is common not only to species of this genus, but also to the Rhodniini tribe. Differences in overall colour, the presence of a collar in R. milesi, a longitudinal bevel in R. stali and the precise length of R. colombiensis can be useful distinguishing features. As a result of this study, the key for egg identification proposed by Barata in 1981 can be updated.

Key words: taxonomy - morphology - Rhodnius colombiensis - Rhodnius milesi - Rhodnius stali

Chagas disease is one of the most widespread diseases in Latin America, with a total of one million people either infected with Trypanosoma cruzi or living in high-risk areas. Therefore, this disease is considered to be a serious public health problem in the 17 countries of this region.

After years of control activities, vector-borne transmission is currently on the decline and transfusional transmission has been interrupted as a result of preventive measures in the blood bank system. Nevertheless, large contingents of infected individuals still live in endemic areas.

Numerous factors hinder the total elimination of Chagas disease. One factor is the presence of widely distributed wild or peridomiciliary vectors in the neotropical region. According to recent observations, vectors that were previously considered to be irrelevant (secondary species) have gained epidemiological importance as they move into the niches that were once occupied by controlled species. Another important factor concerns the recent increase in oral transmission through the ingestion of contaminated food; this is particularly true in the Amazon.

A total of 141 triatomine species are currently recognized and these are distributed from the Southern United States to Southern Argentina and with some representation in Old World countries (Galvão et al. 2003, Forero et al. 2004).

\footnotetext{
Financial support: Chagas Disease Intervention Activities/European Community, IOC-Fiocruz/SVS/MS, CNPq, Capes

+ Corresponding author: carolms@ioc.fiocruz.br

Received 28 January 2009

Accepted 12 August 2009
}

The genus Rhodnius is comprised of 16 potential vector species that have important morphological similarities (Galvão et al. 2003). Rhodnius is considered to be one of the most taxonomically complex genera in the subfamily Triatominae. Previous studies have adopted several approaches to better define the different Rhodnius species and their interrelations. These approaches have included the study of eggs (Barata 1981, Obara et al. 2007), genital morphology (Lent \& Jurberg 1969), salivary gland morphology (Santos et al. 1997), ribosomal DNA (Monteiro et al. 2000, Naegele et al. 2006), biogeography and phylogeny (Schofield \& Dujardin 1999, Abad-Franch \& Monteiro 2007, Paula et al. 2007).

In 1993, Lent et al. described Rhodnius stali using specimens from Northern Brazil that were thought to be Rhodnius pictipes (Stål, 1872). The authors noted that, in addition to gross morphological differences such as smaller total length (TL) and a smaller ratio between the ante and post-ocular regions, there were also differences in the genitalia. Therefore, they described a new species (R. pictipes and $R$. stali); however, this species was considered to be cryptic because for many years it had remained indistinguishable from $R$. pictipes. Both display phallic structures that are not found in other species of the genus, such as the phallosome ( $\mathrm{Ph}$ ) support $(\mathrm{SPh})$, bifid median process of the pygophore and an absence of the $\mathrm{Ph}$ process $(\mathrm{PrPh})$, which could be considered a link between the tribes Rhodniini and Triatomini (Jurberg et al. 1998). However, this assumption was refuted by some DNA sequence-based comparisons (Monteiro et al. 2000, Hypsa et al. 2002, Paula et al. 2007). R. stali is a typically wild species that lives in association with palm trees, birds' nests and mammals. It is also known to invade homes and it is often attracted to light (Lent \& Wygodzinsky 1979. 
In 1999, Mejia et al. studied a specimen that was initially believed to be Rhodnius pallescens (Barber, 1932) or Rhodnius prolixus (Stål, 1859). However, when the morphology was analyzed in detail, it proved to be a new species (Rhodnius colombiensis). Differentiation from the other species was based on morphometric analysis of differences in the cephalic characteristics and differences between some structures of the male genitalia, such as the $\mathrm{Ph}, \mathrm{PrPh}$, conjunctival process 2, conjunctival process 3 , endosome process and median process of pygophore (PrP). The typical specimens of this species were captured from palm trees (Athalea butyracea) in Tolima, Colombia.

In 2000, Carcavallo et al. (Valente et al. 2001) described the most recent species of the genus, Rhodnius milesi, using a specimen from Bragança, Pará (PA), Brazil, that has also been captured in a palm tree (Maximiliana regia and Attalea speciosa). Despite a distinct geographic distribution, it was characterized as being closely related to Rhodnius dalessandroi Carcavallo \& Barreto, 1976. The most important characteristics used to separate these two species were the relationships between the head, the rostral segments and the scutellum; however, a second $\mathrm{PrPh}$ is found on the male genitalia of only Rhodnius nasutus.

Although these species are known to represent distinct taxa, they can share morphological characteristics and/or geographical distribution with other species from the genus Rhodnius; for example, $R$. pictipes with $R$. stali, $R$. colombiensis with Rhodnius ecuadoriensis and $R$. pallescens, $R$. milesi with $R$. dalessandroi (Carcavallo et al. 2000).

The current study is motivated by the need for a more precise taxonomic identification of these potential vectors that is based on the characteristics of the eggs. This issue is pertinent because, in some cases, only eggs or nymphs are found in human dwellings. For a more complete understanding of Rhodnius eggs, we begin with a description of eggs from $R$. colombiensis, $R$. milesi and $R$. stali, which was obtained using optical microscopy (OM), scanning electron microscopy (SEM) and biometry. To update the key proposed by Barata (1981), their characteristics were compared with those of other Rhodnius species.

\section{MATERIALS AND METHODS}

We describe eggs that were obtained from specimens maintained in the insectary of the National and International Reference Laboratory for Triatomine Taxonomy, Instituto Oswaldo Cruz. The parental specimens came from the following localities: $R$. colombiensis from Colombia (Tolima Department, Coyaima Municipality), R. milesi from Brazil (PA, Bragança municipality) and R. stali from Bolivia (La Paz Department, Alto Beni municipality).

We selected a pair of adults from each species, according to the original descriptions (Lent et al. 1993, Mejia et al. 1999, Valente et al. 2001). The specimens were separated and observed daily. After oviposition, we collected the embryonated eggs, the hatched eggs, the exochorion from hatched eggs and the operculum for systematic observations.
OM analyses were based on the observations of 10 eggs. The operculum was detached and mounted between a slide and a slide cover, without adding any solution. Drawings of the eggs were performed using a stereoscopy microscopy with a camera lucida.

For SEM analysis, we used five eggs from each species. The eggs were cleaned and fixed with double-sided sticky tape on metallic stands of $1.2 \mathrm{~cm}$ diameter. Thereafter, the material was coated with gold and observed under a JEOL ${ }^{\circledR}$ JSM T-330A SEM that was operated at 15 $\mathrm{kV}$. The images were photographed and processed using Adobe Photo Shop 6.0 software.

For biometric analyses, which included measurements of the TL and maximum width, 30 eggs from each species were selected at random from a stock of eggs. Standard measurements were performed with graduated eyepieces that were coupled to a stereoscopic microscope. For statistical analysis, the data were compared using analysis of variance and specifically the TukeyKramer test (5\%), with JMP ${ }^{\circledR}$ software.

\section{RESULTS}

R. colombiensis - The general aspects were ellipsoid and elongated. The general colour was light brown to yellowish immediately after oviposition, but changed to salmon-pink before hatching, with highlighted dark brown pigmented ring just below the neck and translucent shells (Forattini \& Barata 1974).

The collar was absent, the neck was long and narrow, lateral flattening was frequently present and brown, like the ring. The chorial rim was without pigmentation, unlike R. ecuadoriensis (Lent \& León, 1958) and the longitudinal bevel was absent (Fig. 4A).

The operculum was slightly flat, with a general dark brown colour, like the above-mentioned ring and thus with a darker shade than the egg body as a whole, with translucent and whitish borders. The opercular border was narrow and darker in colour than the tegument. In some cases there was a slight inclination of the operculum in relation to the lateral flattening.

The overall aspect of the exochorion was uniform. Both the tegument on the egg body and the operculum consisted of polygonal areas that varied between pentagonal and hexagonal cells, although the majority was hexagonal (Fig. 3Ab, e).

Under OM, we observed small central orifices at the entrance of the tubes (Fig. 3Ab), refringent and thus less evident limiting lines (LL) (Fig. 6A) and granulations that were difficult to see. Under SEM, due to the presence of granulations, the LL had a slightly wrinkly aspect and the granulations covering the tegument were irregular in size, were clumped and apparently were more concentrated at the base of the funnels (Fig. 6D).

R. milesi - The general aspects were ellipsoid and robust and the general colour was whitish immediately after oviposition but changed to salmon-pink before hatching, slightly shiny, translucent shells. The presence of a neck was similar to $R$. nasutus (Stål, 1859, Barata 1981) and a collar (Forattini \& Barata 1974) was absent in $R$. colombiensis and $R$. stali. There was slight lateral flattening (Figs 3B, 4B). 


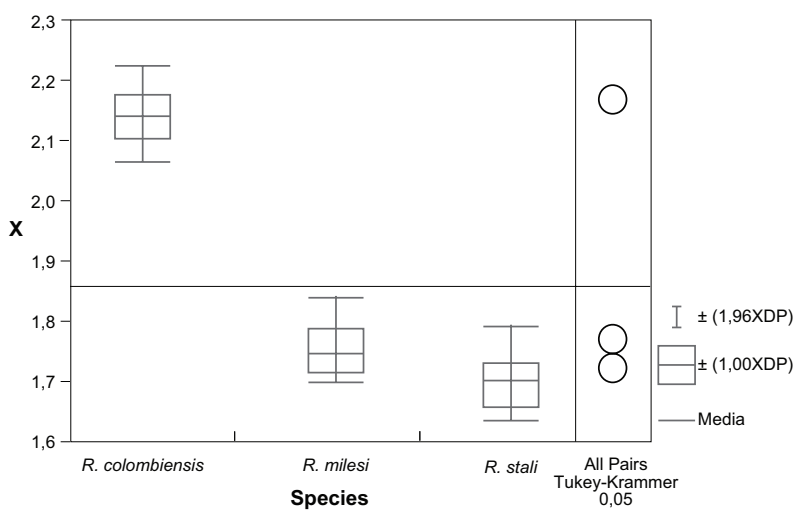

Fig. 1: statistical comparison of length of eggs from Rhodnius colombiensis, Rhodnius milesi and Rhodnius stali. X: mean values for each species according to the Tukey-Kramer test (5\%) represented by circles.

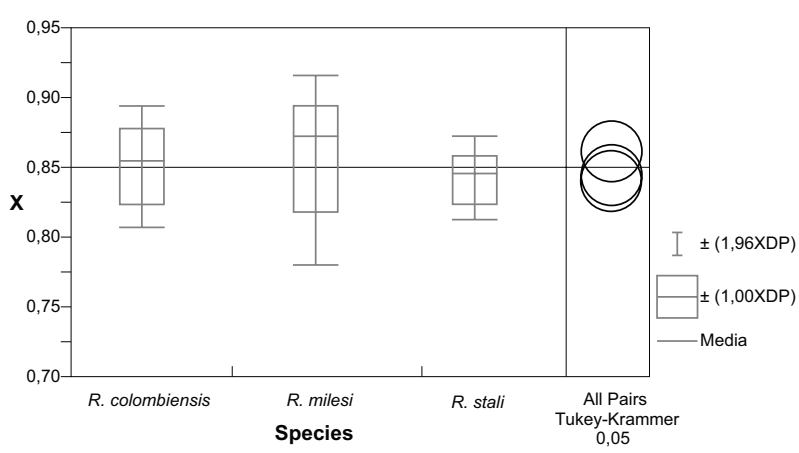

Fig. 2: statistical comparison of width of eggs from Rhodnius colombiensis, Rhodnius milesi and Rhodnius stali. X: mean values for each species according to the Tukey-Kramer test (5\%) represented by circles.

The operculum was slightly flat and the general colour was brownish, darker than the tegument, with whitish borders. The opercular border was narrow, with a slight inclination of the operculum in relation to the lateral flattening. The overall aspect of the exochorion was uniform, with funnels apparently shallower than in $R$. colombiensis and R. stali (Fig. 6B, E). On both the tegument and the operculum, polygonal areas varied from pentagonal to hexagonal, with predominantly hexagonal cells. Under OM, we observed small orifices at the entrance of the tubes (Fig. 3B). The LL were slightly salient, straight, narrow and difficult to see because of the dense covering of granulations in this area (Fig. 6B). Granulations were irregular and randomly distributed near the LL (Fig. 6E).

R. stali - The general aspect was ellipsoid and the general colour was brownish to gold immediately after oviposition and changed to light brown before hatching. The neck was quite narrow and long and the collar was absent, as with $R$. colombiensis (Fig. 5C). Lateral flattening was present, varying to a longitudinal bevel in some cases, which is very similar to $R$. pictipes (Barata 1981) (Fig. 4C).
The operculum was slightly flat, the general colour was brownish, with translucent and whitish borders and lighter chorial rim and the polygonal areas were well-delineated as seen in R. pictipes (Barata 1981). The opercular border was narrow in some cases, with a slight inclination of the operculum in relation to the lateral flattening, similar to the others species studied. The general aspect of exochorion was uniform, with funnels apparently longer than in $R$. colombiensis and $R$. milesi (Fig. 6C, F). Similar patterns to the other species studied here were observed, with the tegument and operculum presenting polygonal areas that varied from pentagonal to hexagonal, with the majority being hexagonal. In OM, under transparent stage, we observed small orifices opening to the tubes (Fig. 3C). Unlike R. milesi and $R$. colombiensis, LL in $R$. stali were prominent, large, smooth, straight and sufficiently clear when observed under SEM (Fig. 6F); these were similar to those in Rhodnius paraensis Sherlock, Guitton \& Miles, 1977 (Barata 1981). Granulations are faint and difficult to observe under SEM.

Table shows the values of the means and standard deviations of length $(1.70-2.15 \mathrm{~mm})$ and width $(0.84-0.86 \mathrm{~mm})$, which showed significantly different means. According to the Tukey-Kramer test ( $\mathrm{p}<0.05)$, in TL, eggs from $R$. colombiensis differed from R. milesi and R. stali (Fig. 1), but there was no significant difference in width (Fig. 2).

\section{TABLE}

Average (X) and standard deviation (SD) of length and width (mm) of eggs of Rhodnius colombiensis,

Rhodnius milesi Carcavallo and Rhodnius stali

\begin{tabular}{lccccc}
\hline & & \multicolumn{2}{c}{ Length } & \multicolumn{2}{c}{ Width } \\
\cline { 3 - 6 } Species & $\mathrm{n}$ & $\mathrm{X}$ & $\mathrm{SD}$ & $\mathrm{X}$ & $\mathrm{SD}$ \\
\hline R. colombiensis & 30 & $2.15^{a}$ & 0.06 & 0.85 & 0.03 \\
R. milesi & 30 & 1.74 & 0.05 & 0.86 & 0.05 \\
R. stali & 30 & 1.70 & 0.04 & 0.84 & 0.03 \\
\hline
\end{tabular}

$a$ : values significantly different (5\%) according to TukeyKramer test.

\section{DISCUSSION}

Pinto (1924) conducted pioneering morphological studies on triatomine eggs and distinguished the eggs of Triatoma brasiliensis (Neiva, 1911) from those of other Triatominae species in Brazil. Later, Galliard (1935) demonstrated differences between the eggs of $R$. prolixus, Triatoma vitticeps (Stål, 1859), Triatoma dimidiata (Latreille, 1811), Triatoma rubrovaria (Blanchard, 1843) and Triatoma protracta (Uhler, 1894), using OM. Still later, several authors included egg morphology as a tool for the description and characterization of various triatomine species (Abalos \& Wygodzinsky 1951, Barth \& Muth 1958).

Barata (1981) used both OM and SEM to enable detailed descriptions of the macroscopic and exochorial 

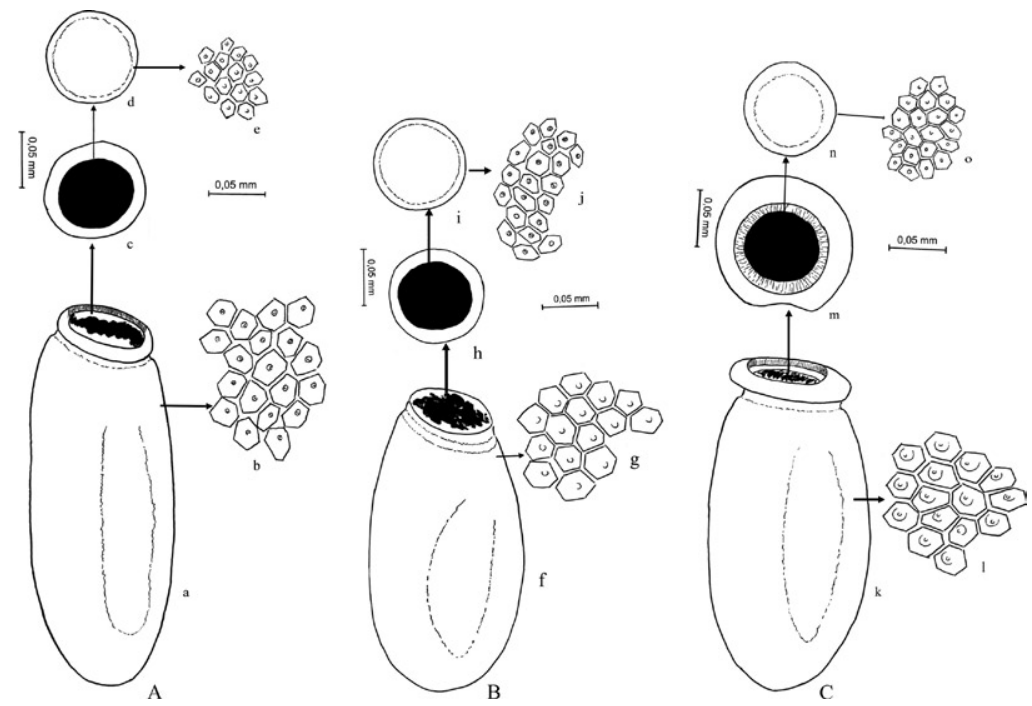

Fig. 3: eggs, under optical microscope (OM). A: Rhodnius colombiensis; B: Rhodnius milesi; C: Rhodnius stali; a, $\mathrm{f}$, k: general aspect of egg; $\mathrm{b}$, $\mathrm{g}, \mathrm{l}$ : exochorion, pentagonal and hexagonal cells; c, h, m: egg without operculum, upper view; $\mathrm{d}, \mathrm{i}, \mathrm{n}$ : operculum; e, j, o: exochorion, pentagonal and hexagonal cells.
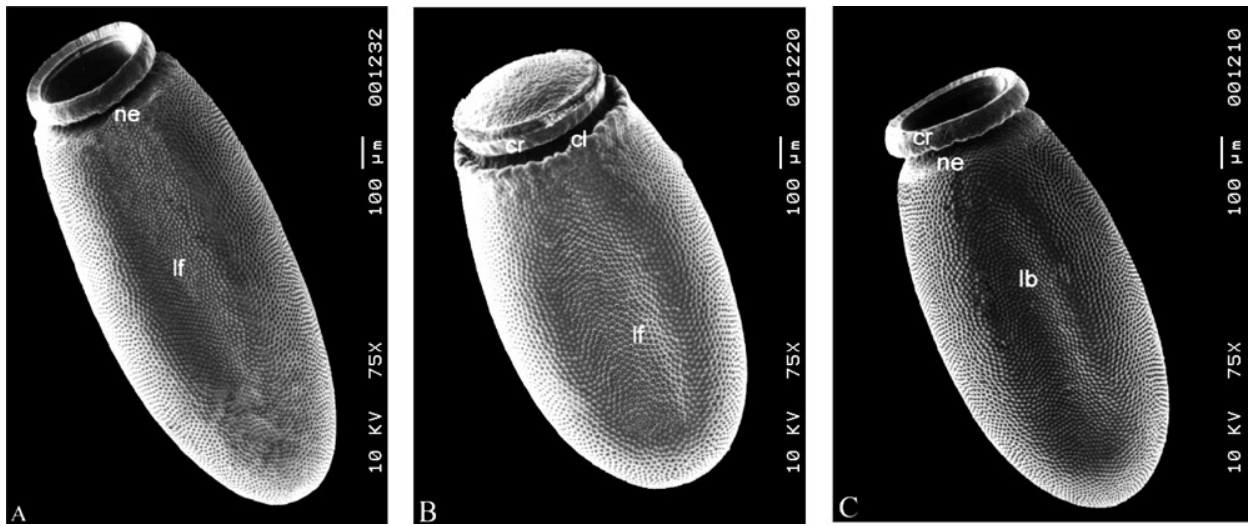

Fig. 4: general aspect of eggs under scanning electron microscopy (75X). A: Rhodnius colombiensis; B: Rhodnius milesi; C: Rhodnius stali; cl: collar; cr: chorial rim; lf: lateral flattening; lb: longitudinal bevel; ne: neck; ob: opercular border (Barata 1981).

characteristics of 10 species from the genus Rhodnius (Stål, 1859) and created a key for classifying species by egg morphology. Various authors (Rosa et al. 2000, 2003) have since adopted this approach. After Barata (1981), many species have been described or re-described on the basis of egg morphology (Sandoval et al. 2007). Using these tools, we observed similarities in the exochorial architecture, such as the predominance of pentagonal cells and varying degrees of lateral flattening; these features are common not only to species of the genus, but also to the Rhodniini tribe. We also detected differences among the three species, with $R$. colombiensis typically displaying an elongated general aspect, $R$. milesi being the only species studied that contains a collar and $R$. stali presenting a longitudinal bevel.

We showed that $R$. colombiensis eggs are generally similar to those of R. pallescens and R. ecuadoriensis (Barata 1981); this corroborates Carcavallo et al. (2000), who suggested a $R$. pallescens complex that includes $R$. colombiensis, R. ecuadoriensis and $R$. pallescens, based on their biological, morphological and ecological similarities.

The collar has been seen in $R$. milesi, R. nasutus, Rhodnius neglectus, Rhodnius neivai, $R$. pallescens and R. paraensis (Barata 1998). However, although Carcavallo et al. (2000) suggested the formation of a specific complex with $R$. milesi and $R$. dalessandroi, it was not possible to verify either similarities or differences between them, due to a lack of literature on $R$. dalessandroi.

$R$. stali exhibited prominent LL and granulations that were very similar to $R$. paraensis and $R$. pictipes (Barata 1981). R. stali shares some characteristics with $R$. pictipes, including the aspect of the opercular border, which is only seen in these two species and the general aspect of the exochorion. Other authors, such as Jurberg et al. (1998), have pointed to the similarity between these two species when studying phallic structures; they have highlighted 

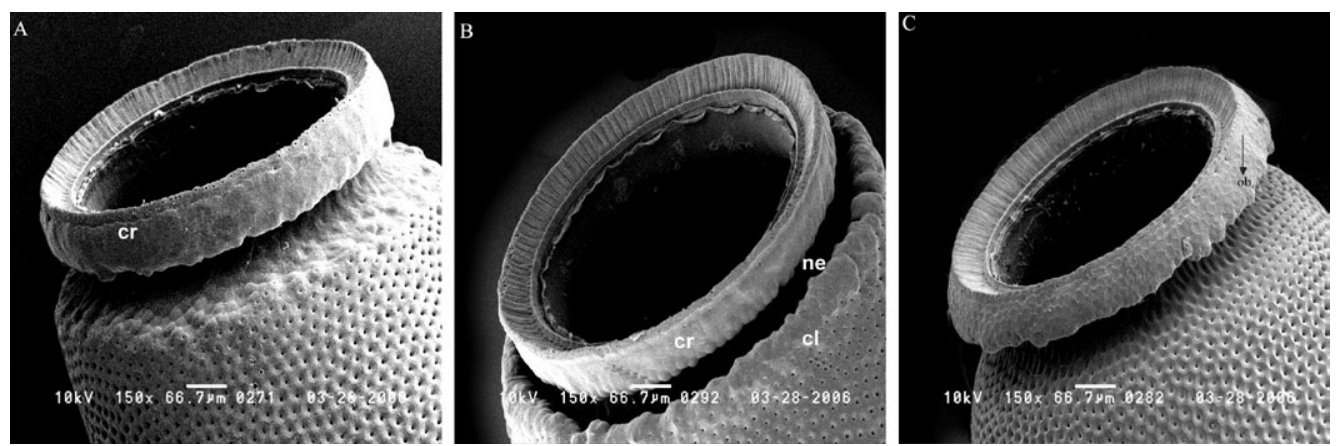

Fig. 5: detail of the opening of operculum under scanning electron microscopy (150X). A: Rhodnius colombiensis; B: Rhodnius milesi; C: Rhodnius stali; cr: chorial rim; cl: collar; ne: neck; ob: opercular border; (Barata 1981).
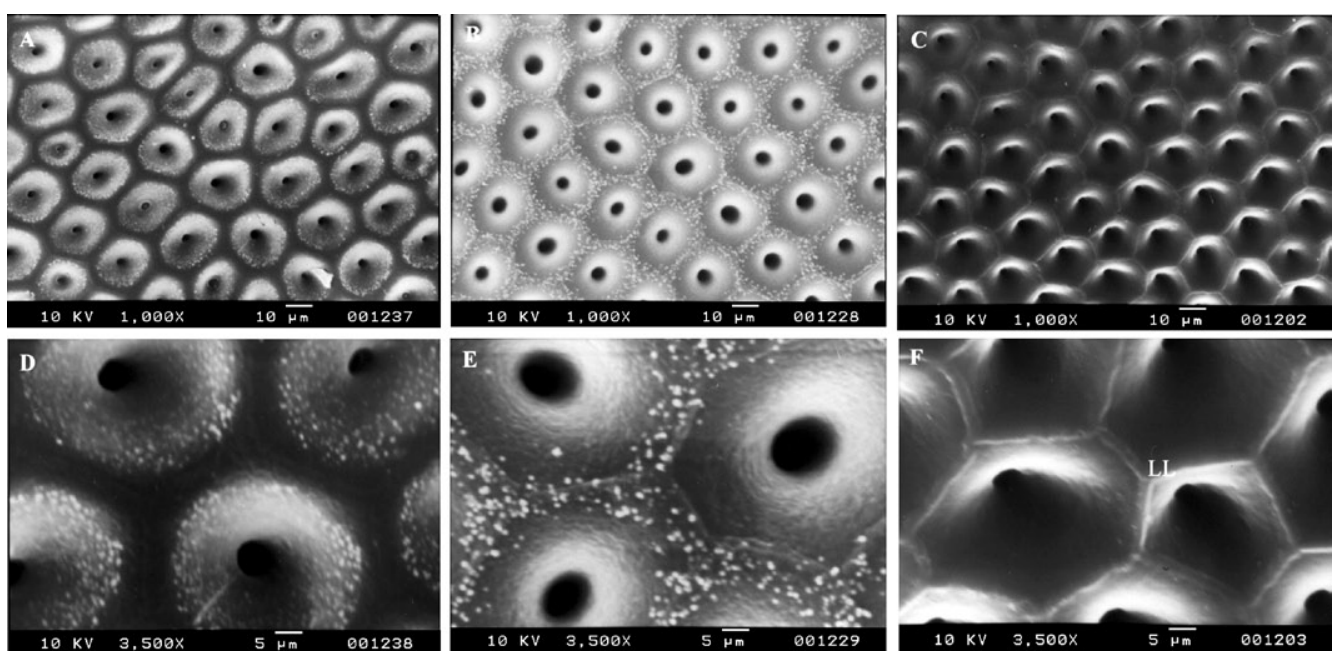

Fig. 6: general aspect of exochorion under scanning electron microscopy (1000X/3500X), Rhodnius colombiensis. A, D: Rhodnius milesi; B, E: Rhodnius stali; C, F: limiting lines (LL) (Barata 1981).

the fact that only these two species display characteristics of the tribe Triatominii, including the $\mathrm{SPh}$, bifid median PrP and the lack of a PrPh. Carcavallo et al. (2000) also corroborated the presence of these similarities when they suggested the constitution of specific complexes in genus Rhodnius, based on similar morphological and/or geographical distribution; thus, the $R$. pictipes complex is proposed to consist of $R$. pictipes and $R$. stali.

From our biometric analysis, we found that $R$. colombiensis was the longest eggs $(2.15 \pm 0.06 \mathrm{~mm})$ and $R$. stali was the shortest $(1.70 \pm 0.04 \mathrm{~mm})$. However, there was only a statistical difference (Tukey-Kramer test, $\mathrm{p}<$ 0.05 ) in the length of the eggs that could be used to distinguish $R$. colombiensis from R. milesi and R. stali.

Our results constitute the first morphological, ultrastructural and biometric study of eggs from $R$. milesi, $R$. colombiensis and $R$. stali. They provide a major contribution to the specific characterization and recognition of this taxon and thus enable future comparative studies with another Rhodnius species. This study also provides data that can be used to update the egg identification key that was proposed by Barata (1981), which provides further support for the utility of these tools.
The following keys are an update of Barata (1981), including $R$. colombiensis, R. milesi and R. stali.

Key to identification of the eggs of 13 Rhodnius species, based on exochorial characteristics (to be used with $O M$ )

1. Eggs with white or whitish shells.......................... 2

- Eggs with brownish shells ................................... 10

2. Eggs with collar ..................................................... 3

- Eggs without collar .................................................... 6

3. Dark brown operculum. LL smooth, narrow, straight and scarcely refringent ...................................... 4

- Pale brown operculum. LL scarcely evident, wrinkled, wide, irregular and non-refringent. Granulations large, abundant and covering the tegument evenly, including the LL............................................................ 5

4. Very shallow funnels, with rounded edges, in histological cross-section, with no evidence of a demarcation of LL. The latter appear faintly, not salient. Irregular granulations, mostly large, distributed irregularly on the tegument nasutus 
- Funnels with slightly sharp borders in histological cross-section, with faint demarcation of LL. LL frequently demonstrable, smooth, narrow, straight and scarcely refringent. Granulations tiny, distributed evenly on the tegument neglectus

5. Eggs stocky, with a short, wide neck, collar with extensions that cover the neck .................................milesi

- Eggs elongated, with long, narrow neck ....... neivai

6. Deep funnels, with characteristic honeycomb aspect. LL refringent and easy to see. Granulations easy to see, frequently large, abundant and more concentrated in the LL area.....

- Shallow funnels, without characteristic honeycomb aspect. LL scarcely refringent and thus difficult to see. Granulations difficult to see, tiny or irregular. Eggs elongated, with apparently narrow neck

.... 9

7. Funnels with sharp borders, ending in prominent design of the LL. Follicular tubes frequently short, with irregular width, straight or curved, with an apical dilatation. Eggs elongated, with an apparently normal neck ...prolixus

- Funnels with rounded, smooth borders, that is, without prominent design of the LL. Follicular tubes long and thin with slight curvatures and apical dilatation. Eggs stocky, with apparently wide neck ... robustus

8. On histological cross-section, the borders of the funnels are rounded, ending in small bevelled protuberances in relation to the design of the LL. Irregular granulations, with irregular distribution. In cross-section, follicular tubes long, with striking apical dilatation ........domesticus

- On histological cross-section, the borders of the funnels are rounded, ending in wide bulging protuberances in relation to the design of the LL. Tiny, sparse, granulations, frequently more concentrated in the area of the LL. Follicular tubes short, wide, with slight apical dilatation

(albinistic eggs)

9. Eggs with heavily pigmented shells in the area of the operculum, collar and/or longitudinal bevel ......... 10

- Eggs with homogeneous colour in these areas.....11

10. Eggs with light golden sheen. Absence of collar and longitudinal bevel. Operculum and ring situated in the area of the collar, with darker brown colour ......... 12

- Presence of collar, although with slight expansions. Operculum, collar and longitudinal bevel with dark brown colour pallescens

11. Eggs with collar 13

- Eggs without collar, narrow neck. Exochorion with uniform and clean aspect, even when viewed under a stereoscopic lens. LL easy to see, wide, smooth, straight and highly refringent . .14

12. Eggs yellowish-brown, chorial rim without darker-coloured ring colombiensis

- Eggs light brown, chorial rim with darkercoloured ring ecuadoriensis

13. Eggs very pale brown and slight bronzed sheen. Collar with slight expansions. Eggs elongated, with well- defined shape. Exochorion with a uniform and clean aspect, even when viewed under a stereoscopic lens. LL difficult to see, straight, smooth, straight and non-refringent, when visible pallescens

(albinistic eggs)

- Eggs with a heavier brown colour, with no sheen. Collar with evident expansions, practically covering the neck. Eggs stocky, with poorly defined shape. Exochorion with an irregular and dirty aspect, even when viewed under a stereoscopic lens. LL easy to see, wide, smooth, straight and highly refringent. paraensis

14. Eggs bronze-coloured, with a slight golden sheen. Sharp inclination of the operculum in relation to the lateral flattening .pictipes

- Eggs golden brown, shells with more rounded sides, or more bulgy eggs. Slight inclination in relation to lateral flattening stali

Key to identification of eggs of 13 Rhodnius species, based on exochorial characters (to be used with SEM)

1. Eggs with collar......................................................... 2

- Eggs without collar ................................................... 7

2. Absence of longitudinal bevel. Collar with evident expansions.

- Presence of longitudinal bevel. Collar with slight expansions. LL absent or designed by the lack of granulations. Granulations tiny, distributed abundantly and uniformly or scarcely and irregularly. Funnels frequently with spheres pallescens

3. Granulations distributed regular or irregularly on the tegument .................................................................. 4

- Granulations forming map-like drawings when agglutinated. LL easy to see, prominent, large, smooth and straight. paraensis

4. Funnels not very deep, with characteristic honeycomb aspect .....

- Shallow funnels, without characteristic honeycomb aspect. Absence of LL, designed by the concentration or lack of granulations. Granulations irregular, frequently forming clumps nasutus

5. LL difficult to see, designed by the concentration of granulations. Granulations large, abundant, distributed regularly on the tegument, scarcely in the funnels but frequently forming clumps, including on the LL.... 6

- Absence or presence of LL narrow, straight, with faint demarcation, wrinkled, visible by the lack of granulations. Granulations tiny, abundant, distributed evenly on the tegument neglectus

6. Collar with expansions not covering the neck...neivai - Collar with expansions covering the neck......milesi

7. Granulations easy to see........................................ 8

- Granulations difficult to see............................. stali

8. Granulations distributed regular or irregularly, not forming map-shaped patterns when agglutinated......... 9

- Granulations forming map-shaped patterns when agglutinated. LL easy to see, prominent, large, smooth and straight 
9. LL with no evidence of demarcation and scarcely prominent. Granulations tiny and rarely agglutinated ... 10

- LL scarcely evident or easy to see. .11

10. LL with no evidence. colombiensis

- LL large, straight and wrinkled. Tiny and sparse granulations, frequently more concentrated in the area of LL ecuadoriensis

11. Irregular, large and abundant granulations, more concentrated around the LL. LL easy to see, prominent, large, frequently wrinkled and straight..............prolixus robustus

- Irregular granulations with irregular distribution, frequently sparse, covering or not the LL. LL with faint demarcation, prominent, narrow, smooth and straight ... domesticus

\section{ACKNOWLEDGEMENTS}

To Vanda Cunha, for maintenance of the insects in the insectary and daily observations.

\section{REFERENCES}

Abad-Franch F, Monteiro FA 2007. Biogegraphy and evolution of Amazonian triatomines (Heteroptera: Reduviidae): implications for Chagas disease surveillance in humid forest ecorregions. Mem Inst Oswaldo Cruz 102: 57-69.

Abalos JW, Wygodzinsky P 1951. Las Triatominae Argentinas (Reduviidae: Hemiptera), Instituto Médico Regional, Tucumán, 178 pp.

Barata JMS 1981. Aspectos morfológicos de ovos de Triatominae II - Características macroscópicas e exocoriais de dez espécies do gênero Rhodnius Stål, 1859 (Hemíptera: Reduviidae). Rev Saude Publ 15: 490-542.

Barata JMS 1998. Macroscopic and exochorial structures of Triatominae eggs. Estruturas macroscópicas e exocoriais de ovos de Triatominae. In RU Carcavallo, I Galíndez Girón, J Jurberg, H Lent, Atlas of Chagas' disease vectors in the Américas, vol. II, Editora Fiocruz, Rio de Janeiro, p. 409-448.

Barth R, Muth H 1958. Estudos anatômicos e histológicos sobre a subfamília Triatominae (Heteroptera: Reduviidae). VIII. Observações sobre a superfície de ovos de espécies mais importantes. Mem Inst Oswaldo Cruz 56: 197-208.

Carcavallo RU, Jurberg J, Lent H, Noireau F, Galvão C 2000. Phylogeny of the Triatominae (Hemiptera: Reduviidae). Proposals for taxonomic arrangements. Entomol Vect 7: 1-99.

Forattini OP, Barata JMS 1974. Nota sobre a diferenciação de ovos de Rhodnius neglectus e R. prolixus. Rev Saude Publ 8: 447-450.

Forero D, Weirauch C, Baena M 2004. Synonymy of the reduviid (Hemiptera: Heteroptera) genus Torrealbaia (Triatominae) with Amphibolus (Harpactorinae), with notes of Amphibolus venator (Klug, 1830). Zootaxa [serial on the Internet]. 2004 Aug [cited 2004 October 4]; 670: 1-12. Available from: http://www.mapress. com/zootaxa/list/list2004.html.

Galliard H 1935. Recherches sur les Réduvidés Hématophages Rhodnius et Triatoma. V. Morphologie de l'ouef des Triatomes. Ann Parasit Hum Comp 13: 511-527.

Galvão C, Carcavallo RU, Rocha DS, Jurberg J 2003. A checklist of the current valid species of subfamily Triatominae Jeannel, 1919 (Hemiptera: Reduviidae) and their geographical distribuition with nomenclatural and taxonomic notes. Zootaxa [serial on the Internet]. 2003 May [cited 2003 May 30]; 202: 1-36. Available from: http://www.mapress.com/zootaxa/list/list2003.html.
Hypsa V, Tietz DF, Zrzavý J, Rego ROM, Galvão C, Jurberg J 2002. Phylogeny and biogeography of Triatominae (Hemiptera: Reduviidae): molecular evidence of a New World Origin of the Asiatic clade. Mol Phylogenet Evol 23: 447-457.

Jurberg J, Lent H, Galvão C 1998. The male genitalia and its importance in taxonomy. Genitálias dos machos e sua importância na taxonomia. In RU Carcavallo, I Galíndez Girón, J Jurberg, H Lent, Atlas of Chagas' disease vectors in the Américas, vol. I, Editora Fiocruz, Rio de Janeiro, p. 85-106.

Lent H, Jurberg J 1969. O gênero Rhodnius Stål, 1859, com um estudo sobre a genitália das espécies (Hemiptera: Reduviidae: Triatominae). Rev Brasil Biol 29: 487-560.

Lent H, Jurberg J, Galvão C 1993. Rhodnius stali n. sp., afim de Rhodnius pictipes Stål, 1872 (Hemíptera: Reduviidae: Triatominae). Mem Inst Oswaldo Cruz 88: 605-614.

Lent H, Wygodzinsky P 1979. Revision of the Triatominae (Hemiptera: Reduviidae) and their significance as vectors of Chagas' disease. Bull Am Mus of Nat Hist 163: 125-520.

Mejia JM, Galvão C, Jurberg J 1999. Rhodnius colombiensis sp. n. da Colômbia, com quadros comparativos entre estruturas fálicas do gênero Rhodnius Stål, 1859 (Hemiptera: Reduviidae: Triatominae). Entomol Vect 6: 601-617.

Monteiro FA, Wesson DM, Dotson EM, Schofield CJ, Beard CB 2000. Phylogeny and molecular taxonomy of the Rhodniini derived from mitochondrial and nuclear DNA sequences. Am J Trop Med Hyg 62: 460-465.

Naegele MP, Costa PI, Rosa JA 2006. Polymorphism of the ITS-2 region of the ribosomal DNA of the Triatominae Rhodnius domesticus, R. pictipes, R. prolixus and R. stali. Med Vet Entomol 20: 353-357.

Obara MT, Barata JMS, Silva NN, Ceretti Jr W, Urbinatti PR, Rosa JA, Jurberg J, Galvão C 2007. Estudo de ovos de quatro espécies do gênero Meccus (Hemiptera: Reduviidae: Triatominae) vetores da doença de Chagas. Mem Inst Oswaldo Cruz 102: 13-19.

Paula AS, Diotaiuti L, Galvão C 2007. Systematics and biogeography of Rhodniini (Heteroptera: Reduviidae: Triatominae) based on 16S mitochondrial rDNA sequences. J Biogeogr 34: 699-712.

Pinto C 1924. Biologia do Triatoma brasiliensis Neiva. Sciencia Medica 2: 541-543.

Rosa JA, Barata JMS, Santos JLF, Cilense M 2000. Morfologia de ovos de Triatoma circummaculata e Triatoma rubrovaria (Hemiptera: Reduviidae). Rev Saude Publ 34: 538-542.

Rosa JA, Justino HHG, Barata JMS 2003. Diferença no tamanho de cascas de ovos de colônias de Panstrongylus megistus. Rev Saude Publ 37: 528-530.

Sandoval CM, Pabón E, Jurberg J, Galvão C 2007. Belminus ferroae n. sp. from the Colombian North-east, with a key to the species of genus (Hemiptera: Reduviidae: Triatominae) Zootaxa 1443: 55-64.

Santos CM, Jurberg J, Galvão C, Lent H 1997. Análise morfológica do complexo salivar dos Triatominae (Hemiptera: Reduviidae). Entomol Vect 4: 155-162.

Schofield CJ, Dujardin JP 1999. Theories on the evolution of Rhodnius. Actual Biol 21: 183-197.

Valente VC, Valente SAS, Carcavallo RU, Rocha DS, Galvão C, Jurberg J 2001. Considerações sobre uma nova espécie do gênero Rhodnius Stål, do estado do Pará, Brasil (Hemiptera: Reduviidae: Triatominae). Entomol Vect 8: 65-80. 